\title{
Barnacle demography: evidence for an existing model and spatial scales of variation
}

\author{
Kieran Hyder $^{1, *}$, Mark P. Johnson ${ }^{1}$, Stephen J. Hawkins ${ }^{1}$, William S. C. Gurney ${ }^{2}$ \\ 'Division of Biodiversity and Ecology, University of Southampton, Bassett Crescent East, Southampton SO167PX, United Kingdom \\ ${ }^{2}$ Department of Statistics and Modelling Science, University of Strathclyde, Glasgow G1 1XH, United Kingdom
}

\begin{abstract}
A demographic model tor an open population with space-limited recruitment has been previously proposed and tested using the barnacle Balanus glandula on a single shore in California. The model makes a number of qualitative predictions about population structure. At small scales, areas of high settlement should have on average less free space and fewer cohorts. At a larger unspecified scale $\left(>34.6 \mathrm{~cm}^{2}\right)$ cohort structure should be more variable in areas of high settlement. We attempted to test these qualitative predictions on a number of different spatial scales using the barnacle Semibalanus balanoides. A recruitment gradient was defined for $S$. balanoides around the coast of Anglesey, Wales, with the north having lower recruitment than the south regardless of year. Given this recruitment gradient, a nested ANOVA was used to examine the qualitative predictions of the demographic model at different scales. The qualitative predictions of the demographic model were not generally supported by an analysis of data from Anglesey. Free space and small-scale population variance did not vary between areas of different recruitment density. Barnacle size variation was greater on high recruitment shores at an intermediate scale $(100 \mathrm{~m})$ as predicted by the model. However, this difference was not statistically significant. Even at the scale of individual $5 \times 5 \mathrm{~cm}$ photographs there was no evidence of a positive relationship between barnacle size variance and free space. Possible reasons for the mismatch of the demographic model predictions and empirical observations are discussed. There may be insufficient spatial sampling, insufficient recruitment difference, large-scale variation in mortality and growth rates, or the model assumptions may be incorrect. One important difference between the 2 levels of recruitment is that low recruitment sites had a constant patch size below $25 \mathrm{~cm}^{2}$, whereas the high recruitment sites did not. If patch scale is variable, the predictions of the demographic model will be irrelevant as there is no single scale at which they can be observed. Use of the nested ANOVA technique with logarithmic spatial scales also allows hypotheses to be made about the important spatial scales for future demographic studies using manipulative experiments. For population variance, free space and opercular length the important scales were small $(<1 \mathrm{~m})$, meso- $(100 \mathrm{~m})$, and large scales $(>10 \mathrm{~km})$
\end{abstract}

KEY WORDS: Barnacles Semibalanus balanoides - Demography - Nested ANOVA - Patch and spatial scales - Qualitative model predictions

\section{INTRODUCTION}

Mathematical models are metaphorical descriptions and thus can never be 'correct' (Hillborn \& Mangel 1997). However, there may be a 'best' model, which is more consistent with the data and therefore the most probable. Credence can be added to models in a number of ways, for example, by testing assumptions or fitting to data (Hillborn \& Mangel 1997). One possibility

•E-mail: kieran@soton.ac.uk is to investigate the qualitative predictions of a model in the field. This can be done by evaluating the accuracy of these predictions at sites with different parameter values.

Roughgarden et al. (1985) proposed a demographic theory for open populations with space-limited recruitment using Balanus glandula Darwin as an example. Since then a complementary set of experimental work and mathematical modelling has been used to bring major advances in the understanding of barnacle populations in Californian coastal waters. The simple model was expanded to a metapopulation level (Iwasa 
\& Roughgarden 1985, 1986a, b), and hydrodynamic processes were added (Roughgarden et al, 1988, 1994, Possingham \& Roughgarden 1990, Richards et al. 1995. Alexander \& Roughgarden 1996) in parallel with experimental work (Gaines \& Roughgarden 1985 1987, Gaines et al. 1985, Shkedy \& Roughgarden 1997).

The model originally proposed by Roughgarden et al. (1985) had an open population with density-dependent regulation of population growth, as the per capita recruitment rate decreases with increasing population size (Bence \& Nisbet 1989). The model gives 2 dynamic states: a stable population size proportional to settlement and periodic fluctuations (see Gaines \& Lafferty 1995 for a general review). These states are dependent upon the balance between the increase in area occupied due to settlement and growth and the loss due to mortality. The model gives a rich range of predictions that have rarely been investigated empirically or experimentally (see Gaines \& Roughgarden 1985, Nisbet $\&$ Bence 1989 ). This approach is applicable to any organism with long dispersal and resource limitation, for example, coral reef fish (Hughes 1984, Mapstone \& Fowler 1988), giant kelp (Nisbet \& Bence 1989), and gap dynamic rainforests (Kohyama 1993).

Roughgarden's model was parameterised using field data from 4 quadrats of $34.6 \mathrm{~cm}^{2}$ at 2 sites on a single shore (Gaines \& Roughgarden 1985) and produced a number of qualitative predictions. The model suggests that free space should oscillate in areas of high settlement and should be stable in areas of low settlement. On average free space should be lower in areas with higher settlement, although sufficient spatial replication is required as the free space oscillates. This temporal prediction can be translated into a spatial prediction by looking at the age structure. In areas of high settlement 'waves' of cohorts are observed travelling through the age structure, whereas in areas of low settlement a stable age structure is produced. Thus, there should be more cohorts found in a given area in low settlement areas (Roughgarden et al. 1985). On a larger unspecified scale $\left(>34.6 \mathrm{~cm}^{2}\right)$, the model predicts that there should be more between-patch variation on shores of high settlement. Despite these tractable qualitative predictions and possible generality, the domain of this theory has not been extended in either space or system. Moreover, the initial tests of the model were for a single species on a single shore in California (Gaines \& Roughgarden 1985).

In our study, we attempted to identify the range of spatial scales where the predictions of the model of Roughgarden et al. (1985) are consistent with empirical observations of the demography of the barnacle Semibalanus balanoides. Existing data obtained by the Coastal Surveillance Unit (Marine Science Laboratories, University College of North Wales, Menai Bridge,
Anglesey) were re-analysed to categorise a recruitment gradient on Anglesey, Wales. Given a definition of areas with different levels of recruitment, we used a simple nested analysis of variance technique to test empirically qualitative predictions of the model of Roughgarden et al. (1985). These predictions were that at small scales areas of high recruitment should have fewer cohorts and on average less free space than areas of low recruitment. However, at larger scales size should be more variable in areas of high recruitment.

\section{ORGANISM AND STUDY SITE}

Semibalanus balanoides (L.) is a species found commonly in the intertidal zone of the North Atlantic. Individuals are distributed between mean high water neaps and mean low water neaps (Stubbings 1975). Juveniles mature at 1 to 2 yr (Arnold 1977). Adults are hermaphroditic with internal cross-fertilisation in autumn (Barnes 1992). A single brood is produced per year of 400 to 8000 eggs which hatch internally (Barnes \& Barnes 1968). Larvae are released into the plankton between March and April (Crisp 1964). In the UK cyprids settle between March and July (Hawkins \& Hartnoll 1982, Kendall et al. 1982) and metamorphose into adults.

Many aspects of Semibalanus balanoides biology and ecology have been extensively studied. For example, settlement/recruitment (e.g. Bennell 1981, Hawkins \& Hartnoll 1982, Kendall et al. 1982, Wethey 1985, Minchinton \& Scheibling 1993. Hills \& Thomason 1996); growth (e.g. Barnes \& Powell 1953, Wethey 1983, Sandford et al. 1994); mortality (e.g. Connell 1983, 1985); and interactions with predators (e.g. Connell 1961), algae (e.g. Hawkins 1983), and limpets (e.g. Hawkins 1983, Miller \& Carefoot 1989).

Anglesey is situated off the northwest coast of Wales (see Fig. 1). Five species of barnacles are found intertidally. The most common is Semibalanus balanoides. Balanus crenatus Bruguière is found low on the shore and in the subtidal. Elminius modestus Darwin is found largely in sheltered areas, while Chthamalus stellatus (Poli) and C. montagui Southward are only found at a few exposed West Coast sites (see Bennell 1981). Bennell (1981) found a difference in levels of recruitment between the north and south of the island (see Fig. 1).

\section{MATERIALS AND METHODS}

Following Bennell (1981), we hypothesised that recruitment on the south of Anglesey is always higher than the north of Anglesey regardless of the year. Data were collected monthly on the recruitment of Semibal- 


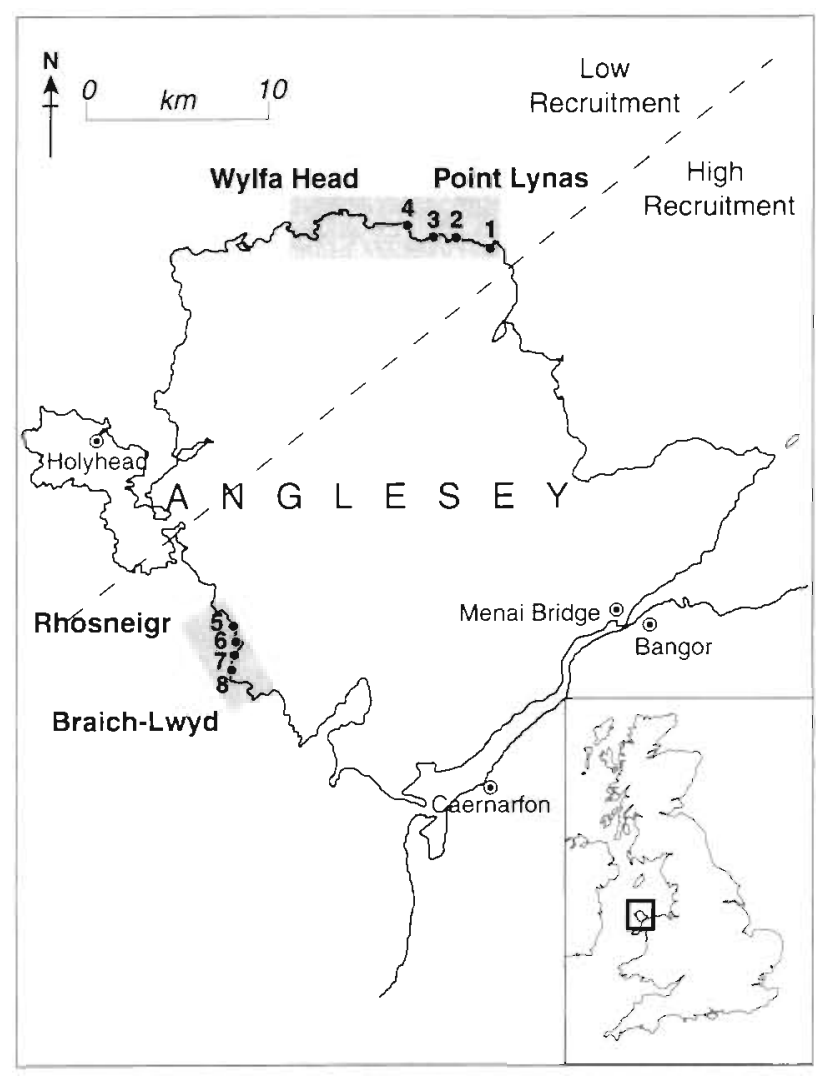

Fig. 1. Anglesey, Wales, study area, sampling sites and proposed recruitment gradient (Bennell 1981). Shores chosen at random between Point Lynas and Wyfla Head in the north and between Rhosneigr and Braich-Lwyd in the south. Numbers indicate shores sampled. 1. Porth Yr Ysgaw; 2: Amlwch; 3: Bull Bay East; 4: Bull Bay West; 5: Porth Nobla; 6: Porth Trecastell north; 7: Porth Trecastell south; 8: Ynysoedd Euon

anus balanoides in $50 \times 50 \mathrm{~cm}$ fixed quadrats on shores on the north and south coasts of Anglesey between 1978 and 1980 (Coastal Surveillance Unit). These data were scaled by dividing by the percentage free space to produce a recruitment rate per unit free space per month. This scaling to free space is valid because barnacle cyprids only settle onto adult tests if the free space is less than $5 \%$ (Gaines \& Roughgarden 1985). This measure of recruitment rate is akin to the settlement rate defined by Roughgarden et al. (1985) as the number of barnacles that settle per unit free space within the time period and survive to the next census.

Analysis of all the 1978-1980 recruitment data would have given a badly unbalanced ANOVA design, as there are missing data. Unbalanced designs are technically complex as it is impossible to derive $F$-ratio tests for some sources of variation; the degrees of freedom are approximate and violations of the assumptions are more likely to affect the likelihood of type I errors (see Underwood 1997 for a general review).
Table 1. Design of 2-way ANOVA to investigate the recruitment gradient on Anglesey (Greek letter denotes fixed factor)

\begin{tabular}{|lcc|}
\hline Source of variation & Levels & Type of factor \\
\hline Region $(\rho)$ & $r=2$ (north, south) & Fixed \\
Year $(Y)$ & $y=3(1978-1980)$ & Random \\
Residuals & $k=10$ & Random \\
\hline
\end{tabular}

Thus, we resampled the total data set at random for north and south of Anglesey to produce a balanced design. Differences between years and sites were tested using a 2-way mixed model ANOVA (Table 1). The linear model used was:

$$
X_{r y k}=\mu+\rho_{r}+Y_{y}+(\rho Y)_{r y}+\epsilon_{r y k}
$$

where $X$ is the recruitment, $\mu$ is the overall mean, $\rho_{r}$ is the effect of the $r$ th region, $Y_{y}$ is the effect of the $y$ th year, $(\rho Y)_{r y}$ is the interaction between the $r$ th region and yth year and $\epsilon_{r y k}$ is the error term. Mean square pooling was used where applicable (see Underwood 1997, for details). Roughgarden et al. (1985) suggested that in areas of low recruitment free space should be constant; however, in areas of high recruitment free space should oscillate. Given a difference in recruitment between the north and south of Anglesey, time series of percentage free space from 1974 to 1984 on 3 shores on the north and 5 shores on the south of Anglesey were examined (Coastal Surveillance Unit). Data were sampled using $50 \times 50 \mathrm{~cm}$ fixed quadrats in the mid shore region. The averages of 3 contiguous mid shore quadrats were tested for periodic fluctuations in free space using autocorrelation techniques.

There is evidence that large- and small-scale recruitment patterns and ordering of sites are temporally consistent in many species with planktonic dispersal; i.e. sites which have low recruitment are always lower than sites that have high recruitment. Small-scale, or within-shore, recruitment differences have been shown to be temporally consistent on scales of 3 to 12 yr for barnacles (Gaines \& Roughgarden 1985, Kendall et al. 1985) and 7 yr for limpets (Bowman \& Lewis 1977). Large-scale, or between-shore, recruitment differences have been shown to be consistent over time scales of 6 yr in mussels (Robles 1997). Connell (1985) observed several populations at several sites over a series of years and found that recruitment at some sites remained consistently higher than others. Thus, there is general evidence for the ranks of recruitment differences being temporally consistent. In this analysis, year was taken as a random factor, which assumes that the sample for each year was drawn at random from the distribution of recruitment over years. Thus, we are able to generalise about variations over 
time. Therefore, in our analysis, if no significant year by region interaction was found, and a significant difference existed between sites, then a temporally consistent recruitment difference was inferred.

Roughgarden et al. (1985) made qualitative predictions about population structures and free space in areas with different levels of settlement. However, few studies measure actual larval settlement; instead they measure recruitment to a defined stage (Connell 1985). Roughgarden et al. (1985) defined settlement in exactly the same way as Connell (1985) defined recruitment: the number of barnacles that settle per unit free space within the time period and survive to the next census. Following this, on small scales $\left(\leq 34.6 \mathrm{~cm}^{2}\right)$ we hypothesised that in areas with high recruitment individuals should be surrounded by individuals of a similar size (i.e. the same cohort) and have on average less free space than populations with low recruitment. At a larger scale $\left(>34.6 \mathrm{~cm}^{2}\right)$ areas of high recruitment should have more variability in size than areas of lower recruitment. A nested ANOVA was used to analyse the variation in a population at different spatial scales, where the top level was a fixed factor and subordinate levels were random factors (see Sokal \& Rohlf 1995 for a general review). The $F$-value was a test of whether each spatial level contributed significantly to the observed total variation (Underwood 1997). This design allowed investigation of the population structure at the level where the recruitment difference was found. Thus, accepting the model's hypotheses about population structure or free space would demonstrate: (1) ability of the model predictions to order sites correctly; (2) give an idea of the robustness of the model; and (3) a spatial scale of applicability of the model to Semibalanus balanoides.

The nested ANOVA was designed to encompass spatial scales from less than $1 \mathrm{~m}$ to the scale of hypothesised recruitment differences $(>10 \mathrm{~km})$, using a total of 360 replicates (Table 2). The shores were chosen at random (see Fig. 1) from a selection of shores chosen to be at least $100 \mathrm{~m}$ in length and accessible. Three sites were chosen at random from possible areas

Table 2. Design of nested ANOVA to test hypotheses from Roughgarden's model (Greek letter denotes fixed factor)

\begin{tabular}{|lccc|}
\hline Source of variation & Levels & Scale & $\begin{array}{c}\text { Type of } \\
\text { factor }\end{array}$ \\
\hline Area of recruitment, $\alpha$ & $a=2$ & $10^{4} \mathrm{~m}$ & Fixed \\
Shore, $\mathrm{S}(\alpha)$ & $s=4$ & $10^{3} \mathrm{~m}$ & Random \\
Site, $\mathrm{Si}(\mathrm{S}(\alpha))$ & $t=3$ & $10^{2} \mathrm{~m}$ & Random \\
Plot, $\mathrm{P}(\mathrm{Si}(\mathrm{S}(\alpha)))$ & $p=3$ & $10^{\mathrm{l}} \mathrm{m}$ & Random \\
Replicates & $n=5$ & $10^{0} \mathrm{~m}$ & Random \\
\hline
\end{tabular}

within $100 \mathrm{~m}$ on each shore and then 3 plots were selected at random from within $10 \mathrm{~m}$ at each site. In August 1997, a $5 \times 5 \mathrm{~cm}$ area of shore was photographed for each replicate, which was about 30 times the maximum adult area measured. This was well above the minimum of 20 times maximum adult area suggested for such studies (Green 1979). Photographs were taken on vertical faces in the middle of the Semibalanus balanoides zone. Images were scanned onto a personal computer and measurements made using the Image Tool programme (developed at the University of Texas Health Science Centre at San Antonio, available by anonymous ftp from maxiad6. uthscsa.edu). Free space was estimated using a 64 point frame and included dead barnacle tests. Population variance was measured by selecting a barnacle at random and measuring its opercular length, and the opercular lengths of its 9 closest neighbours. These measurements were log transformed to remove the linear relationship between mean and variance and then the variance was calculated, a larger variance showing a larger range of sizes (i.e. more cohorts). Opercular length was used because it is a better measure of overall size than shell length and is less subjective when individuals are crowded (Wethey 1983). The size of barnacles was assessed from the opercular lengths of 10 random barnacles measured in each photograph.

These measurements were tested for heterogeneity of variance using Cochran's test (Cochran 1951). If significant, the data were transformed using a logarithmic, square root, or arcsine square root transformation until a minimum value of Cochran's test statistic was obtained. The population variation and free space measurements were analysed using the linear model:

$$
\begin{aligned}
X_{a s t p n}= & \mu+\alpha_{a}+\mathrm{S}(\alpha)_{s(a)}+\operatorname{Si}(\mathrm{S}(\alpha))_{t(s(a)\}}+ \\
& \mathrm{P}(\operatorname{Si}(\mathrm{S}(\alpha)))_{\mathrm{p}\{t(t a \mid)\})}+\epsilon_{n \mid p(t \mid s(a)\}))}
\end{aligned}
$$

where $X$ is the measurement, $\mu$ is the overall mean, $\alpha_{d}$ is the effect of the ath area of recruitment level, $\mathrm{S}(\alpha)_{S|a|}$ is the effect of the sth shore, $\operatorname{Si}(S(\alpha))_{i(s(a))}$ is the effect of the $t$ th site, $P(S i(S(\alpha)))_{p(t)(a)\})}$ is the effect of the $p$ th plot and $\epsilon_{n(p(t) \mid\{\mid d)\})}$ is the error term. Variance components as a percentage of the total were calculated for all the random factors.

Population variation measurements were plotted against free space for the north and south of Anglesey. A Kendall's non-parametric correlation was used to Iook for a significant relationship between the variables. A positive relationship would be expected from the model of Roughgarden et al. (1985), population variance increasing on average with increasing free space.

The opercular lengths were tested for homogeneity of variances and analysed using the model in Table 3. The normal nested ANOVA tests for differences between the means at each level and the comparison 
Table 3. Split ANOVA to test qualitative predictions from Roughgarden et al.'s (1985) model and spatial scales of variation for opercular length (Greek letter denotes fixed factor). Hi: high recruitment area; Lo: low recruitment area; MS: mean squares; $\mathrm{H}$ : among photograph scale; Res: within photograph scale. Fratios for variability are calculated using the larger MS as the numerator and smaller as the denominator. Model prediction can be either 1- or 2-tailed tests. $\neq: 2$ tail $;<$ or $>$ : 1 tail

\begin{tabular}{|c|c|c|c|c|c|}
\hline \multicolumn{2}{|c|}{ Source of variation } & \multicolumn{2}{|c|}{$\mathrm{df}$} & \multirow{2}{*}{$\begin{array}{c}\text { F-ratio } \\
\mathrm{MS}_{\mathrm{u}} / \mathrm{MS}_{\mathrm{S}}\end{array}$} & \multirow{2}{*}{$\begin{array}{c}\text { Model } \\
\text { prediction }\end{array}$} \\
\hline Area & $\alpha$ & 1 & & & \\
\hline Shore & $\begin{array}{l}\mathrm{S}(\alpha) \\
\mathrm{S}(\operatorname{Hi}(\alpha)) \\
\mathrm{S}(\operatorname{Lo}(\alpha))\end{array}$ & 6 & $\begin{array}{l}3 \\
3\end{array}$ & $\begin{array}{c}\mathrm{MS}_{\mathrm{S}} / \mathrm{MS}_{\mathrm{S}_{l}} \\
\mathrm{MS}_{\mathrm{S}_{(, \mathrm{H} l l}} / \mathrm{MS}_{\mathrm{S}_{i}\left(\mathrm{~L}_{0}\right)}\end{array}$ & $\sigma_{\mathrm{S}(1+\mathrm{ti})} \neq \sigma_{\mathrm{S}\{L, a)}$ \\
\hline Site & $\begin{array}{l}\operatorname{Si}(\operatorname{S}(\alpha)) \\
\operatorname{Si}(\operatorname{S}(\operatorname{Hi}(\alpha))) \\
\operatorname{Si}(\operatorname{S}(\operatorname{Lo}(\alpha)))\end{array}$ & 16 & $\begin{array}{l}8 \\
8\end{array}$ & $\begin{array}{c}\mathrm{MS}_{51} / \mathrm{MS}_{\mathrm{p}} \\
\mathrm{MS}_{\mathrm{Si}\left(\mathrm{H}_{1}\right)} / \mathrm{MS}_{\mathrm{Si}(\mathrm{L} 0)}\end{array}$ & $\sigma_{\mathrm{Si}(1), i)} \neq \sigma_{\mathrm{Si}}(\mathrm{LO})$ \\
\hline Plot & $\begin{array}{l}\mathrm{P}(\operatorname{Si}(\operatorname{S}(\alpha))) \\
\mathrm{P}(\operatorname{Si}(\operatorname{S}(\operatorname{Hi}(\alpha)))) \\
\mathrm{P}(\operatorname{Si}(\operatorname{S}(\operatorname{Lo}(\alpha))))\end{array}$ & 48 & $\begin{array}{l}24 \\
24\end{array}$ & $\begin{array}{c}\mathrm{MS}_{\mathrm{p}} / \mathrm{MS}_{\mathrm{H}} \\
\mathrm{MS}_{\mathrm{P}\left(\mathrm{H}_{1} / \mathrm{M}\right.} \mathrm{MS}_{\mathrm{P}_{\mathrm{L}} \mathrm{L} ;}\end{array}$ & $\sigma_{\left.P_{(\mid H}\right)} \neq \sigma_{P(L o)}$ \\
\hline Photo & $\begin{array}{l}\mathrm{H}(\mathrm{P}(\mathrm{Si}(\mathrm{S}(\alpha)))) \\
\mathrm{H}(\mathrm{P}(\mathrm{Si}(\mathrm{S}(\mathrm{Hi}(\alpha))))) \\
\mathrm{H}(\mathrm{P}(\mathrm{Si}(\mathrm{S}(\operatorname{Lo}(\alpha)))))\end{array}$ & 288 & $\begin{array}{l}144 \\
144\end{array}$ & $\begin{array}{c}\mathrm{MS}_{\mathrm{H}} / \mathrm{MS}_{\mathrm{Res}} \\
\mathrm{MS}_{\mathrm{H} i \mathrm{Hi} /} / \mathrm{MS}_{\mathrm{H}(\mathrm{Lo})}\end{array}$ & $\sigma_{H\left(H_{1}\right)} \neq \sigma_{H(L, 0)}$ \\
\hline Residual & $\begin{array}{l}\operatorname{Res}(\mathrm{Hi}) \\
\operatorname{Res}(\mathrm{LO})\end{array}$ & 3240 & $\begin{array}{l}1620 \\
1620\end{array}$ & $M S_{\text {Res, Hil }} / M_{\text {Res!Lol }}$ & $\sigma_{\text {Res(Hi) }}<\sigma_{\text {ResiLos }}$ \\
\hline
\end{tabular}

the 2 areas. The area means were then tested separately to look for significant differences from 1 using a $z$-test. A significant difference would suggest that there was a constant patch size below the $5 \times 5 \mathrm{~cm}$ quadrat scale.

\section{RESULTS}

Firstly, we examined the hypothesis that recruitment was higher on the south than the north of Anglesey. The results of the 2-way ANOVA showed a non-significant year by region interaction and allowed pooling of the mean squared error and interaction terms. After pooling we found a significant difference between regions and between years (Table 4). The difference between years suggests that there was temporal variation in recruitment and regional differences showed recruitment in the south to be higher than the north regardless of year (Fig. 2). Given this recruitment

between levels tests the variability in size at the level of photograph. The predictions of the model of Roughgarden et al. (1985) and the number of tails in the F-ratio are shown (see Table 3 ).

Patch size constancy at a scale of less than $5 \times 5 \mathrm{~cm}$ was assessed by comparing the population variation and variances calculated from the log transformed measurements of size. The population variances were divided by variances in size for each quadrat. If there is no patch scale of less than $5 \times 5 \mathrm{~cm}$, then different sizes of barnacles are distributed at random across the quadrat and the ratio of the size to population variance should be 1 . However, if there is a constant patch scale below $5 \times$ $5 \mathrm{~cm}$, then the population variances would be less than the size variances and the ratio should be less than 1 . The ratios were tested for homogeneity of variances and analysed using the linear model (Eq. 2). A difference at the area level would suggest differences in patch scale in

Table 4. Two-way ANOVA of recruitment with means pooled (interaction non-significant, $\mathrm{p}=0.5184$ ) and non-significant Cochran's test $(C=0.281, \mathrm{df}=6,9, \mathrm{p}>0.05)$. Bold values indicate significance

\begin{tabular}{|lrrrr|}
\hline Source & df & Mean squares & $F$ & p-value \\
\hline Region & 1 & 12.333 & 4.787 & $\mathbf{0 . 0 3 1}$ \\
Year & 2 & 31.949 & 12.637 & $<\mathbf{0 . 0 0 1}$ \\
Pooled & 56 & 2.528 & & \\
\hline
\end{tabular}

difference, we were able to test the qualitative predictions of Roughgarden et al.'s (1985) model.

Only 1 of the 8 shores examined appeared to show oscillatory temporal dynamics (Fig. 3). Other shores tended to have longer-term trends, which could be the result of interannual recruitment variation (Fig. 3). When the series were detrended by differencing between adjacent records, there was no evidence for short-term oscillations. Overall the results are ambiguous. Oscillations could be missed as the data were collected at an inappropriate scale. For example $25 \mathrm{~cm}^{2}$

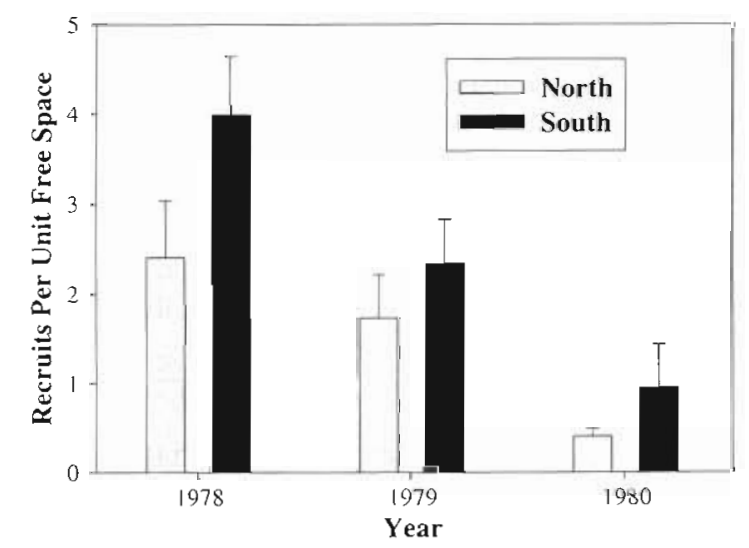

Fig. 2. Semibalanus balanoides. Randomly resampled data for the recruitment per unit free space on the north and south of Anglesey 

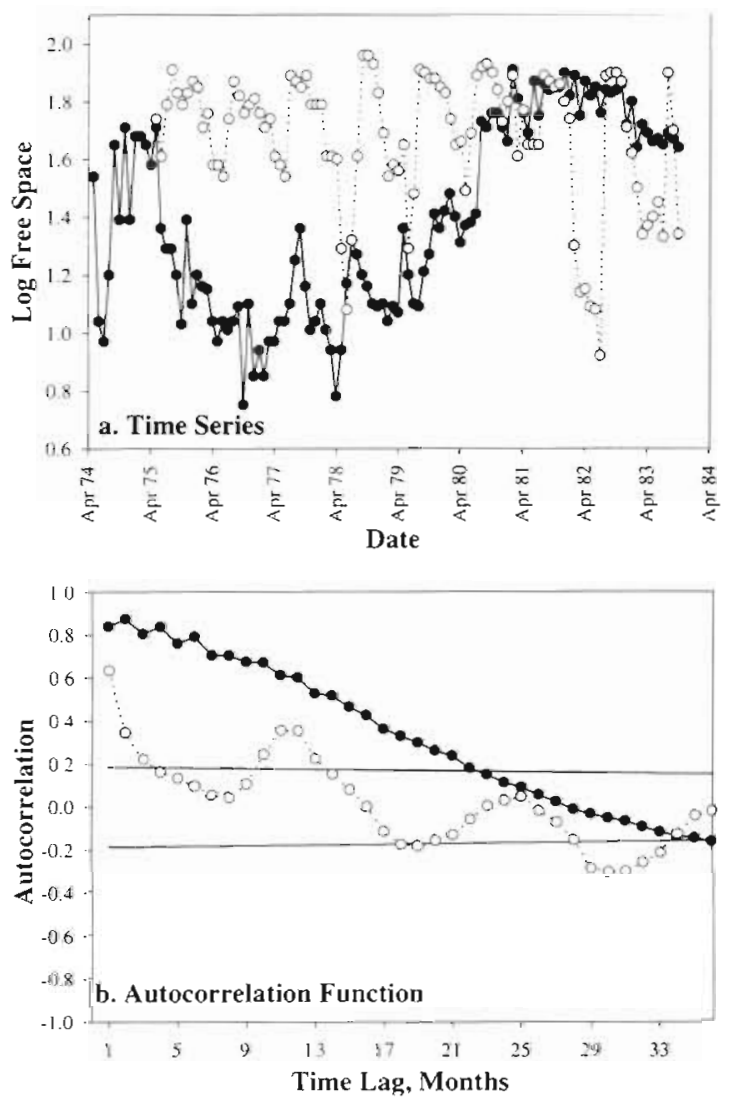

Fig. 3. (a) Time series and (b) autocorrelation function for free space on 1 shore on the north and 1 shore on the south of Anglesey. $(\bullet)$ north shore at Porth Yr Ysgaw; (0) south shore at Ynysoedd Duon

patches cycling independently would not be detected in records from a $2500 \mathrm{~cm}^{2}$ quadrat. However, oscillations are not clear evidence for the demographic model as other reasonable explanations cannot be discounted.

Significant variation in population variance was found at the site level $(100 \mathrm{~m})$. The site level accounted for $9.5 \%$ of the total variation, but $84 \%$ of the variation was found within replicates (Table 5). A variance com-

Table 5. Results of the nested ANOVA for population variance. Cochran's test showed homogenous variances without transformation $(C=0.0598$, df $=72,4, p>0.05)$. Significant values in bold

\begin{tabular}{|c|c|c|c|c|c|}
\hline Source & $\mathrm{df}$ & $\begin{array}{l}\text { Mean } \\
\text { squares }\end{array}$ & $F$ & p-value & $\begin{array}{l}\text { Variance } \\
\text { component } \\
(\% \text { of total) }\end{array}$ \\
\hline Area & 1 & $1.71 \times 10^{-4}$ & 0.326 & 0.589 & - \\
\hline Shore & 6 & $5.26 \times 10^{-4}$ & 1.392 & 0.277 & 2.148 \\
\hline Site & 16 & $3.78 \times 10^{-4}$ & 2.373 & 0.011 & 9.518 \\
\hline Plot & 48 & $1.59 \times 10^{-4}$ & 1.232 & 0.154 & 3.910 \\
\hline Residual & 288 & $1.29 \times 10^{-4}$ & & & 84.424 \\
\hline
\end{tabular}
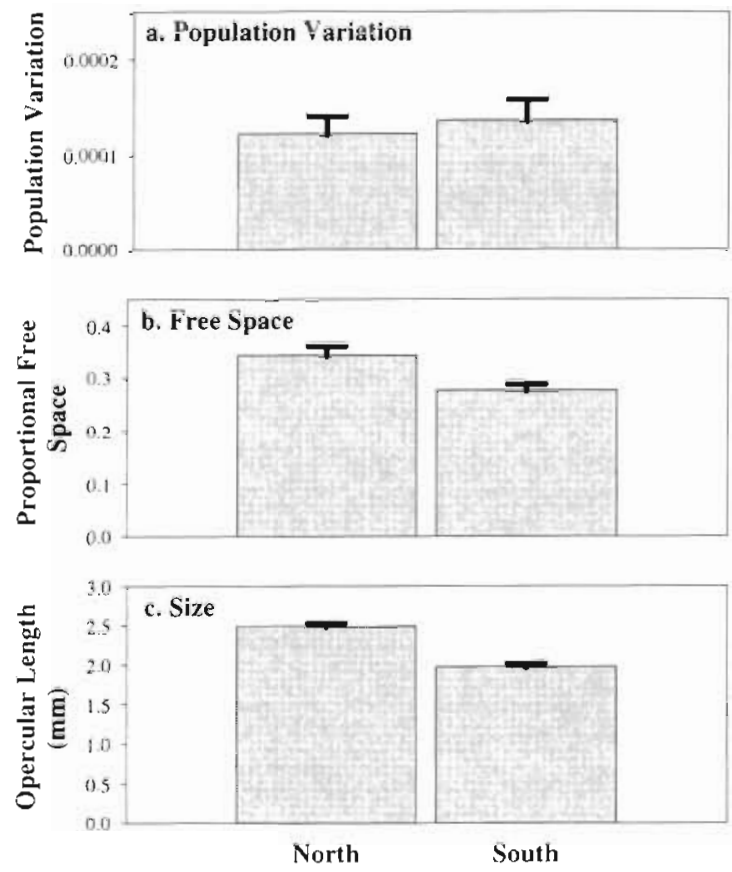

Fig. 4. Sembalanus balanoides. Variation in (a) population variation, (b) free space and (c) mean opercular length in an area of high (north) and low (south) recruitment (means $+\mathrm{SE}$ )

ponent was not calculated for the fixed factor as comparisons of fixed and random factor variance components are not valid (see Underwood 1997 for details). The population variances were equal in the north and south (see Fig. 4a).

There was no difference in the free space available on the north and south of Anglesey; significant differences were found at the shore level $(\mathrm{km})$ and site level $(100 \mathrm{~m})$ (Table 6$)$. The shore and site levels accounted for $13 \%$ of the total variation in each case, but $72 \%$ of the variation was found within. replicates (Table 6). Proportional free space in quadrats ranged from 0.13 to 0.86 in the north and from 0.09 to 0.52 in the south. Average free space for the areas of different recruit-

Table 6. Results of the nested ANOVA for free space. Cochran's test showed homogenous variances with a logarithmic transformation $(C=0.0419$, df $=72,4, p>0.05)$. Significant values in bold

\begin{tabular}{|c|c|c|c|c|c|}
\hline Source & $d f$ & $\begin{array}{l}\text { Mean } \\
\text { squares }\end{array}$ & $F$ & p-value & $\begin{array}{l}\text { Variance } \\
\text { component } \\
\text { (\% of total) }\end{array}$ \\
\hline Area & 1 & 0.672 & 3.222 & 0.123 & - \\
\hline Shore & 6 & 0.208 & 3.104 & 0.033 & 13.178 \\
\hline Site & 16 & 0.067 & 3.726 & $<0.001$ & 13.746 \\
\hline Plot & 48 & 0.018 & 1.044 & 0.402 & 0.640 \\
\hline Residual & 288 & 0.017 & & & 72.435 \\
\hline
\end{tabular}



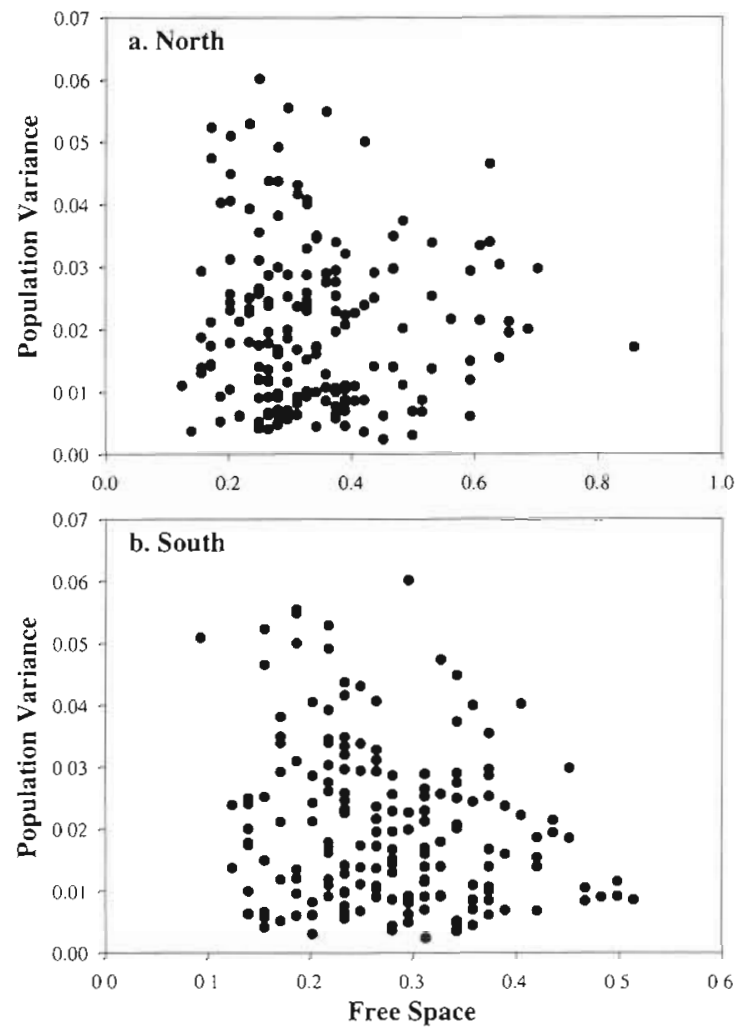

Fig. 5. Semibalanus balanoides. Population variance plotted against free space for each quadrat on the (a) north and (b) south of Anglesey ment appeared to be greater in the north than south (see Fig. 4 b).

A positive relationship between population variation and free space was not found in either the north (low recruitment) or south (high recruitment) of Anglesey (Fig. 5). Non-parametric correlations suggested that there was no relationship in the north (Kendall's $\tau=$ $-0.011, \mathrm{n}=180, \mathrm{p}>0.05$ ) and a negative relationship in the south (Kendall's $\tau=-0.114, \mathrm{n}=180, \mathrm{p}<0.05$ ). The only combination of population variation and free space that did not occur in either area is high population variation with high free space.

Significant variation in size was found at the plot $(10 \mathrm{~m})$, site $(100 \mathrm{~m})$, and recruitment $(10 \mathrm{~km})$ levels with the plot level accounting for $2.4 \%$ and site level accounting for $5.9 \%$ of the total variation (Table 7 ). The significant Cochran's test increases the likelihood of significant results as the variances are not equal (Underwood 1997). About $91 \%$ of the variation was found within the replicates. The test of the residuals showed no difference between areas in small-scale variability (Table 7). However, at the site level there were strong tendencies for differences in spatial variability in the direction predicted by the model (Table 7) with high recruitment sites 3.5 times more variable than low recruitment sites. Size ranged from 0.70 to $5.29 \mathrm{~mm}$ in the north and from in 0.53 to $4.68 \mathrm{~mm}$ the south. On average barnacles were larger in the north than in the south of Anglesey (see Fig. 4c).

Comparison of the variances of the log transformed population variance measurements and variances of

Table 7. Results of the nested ANOVA for size (Cochran's test significant with logarithmic transformation for 360 variances with 9 degrees of freedom, $C=0.03192, \mathrm{p}<0.05)$. Hi: high recruitment area, Lo: low recruitment area. VC: variance component expressed as a percentage of the total (negative variance components are set to zero). Bold values are significant

\begin{tabular}{|c|c|c|c|c|c|c|}
\hline Source & $\mathrm{df}$ & Mean squares & $F$ & p-value & Inference & $\mathrm{VC}(\%$ of total) \\
\hline Area & 1 & 9.437 & 33.64 & $<0.001$ & & - \\
\hline $\begin{array}{l}\text { Shore } \\
\text { High } \\
\text { Low }\end{array}$ & $\begin{array}{l}3 \\
3\end{array}$ & $\begin{array}{l}0.281 \\
0.269 \\
0.292\end{array}$ & $\begin{array}{l}1.116 \\
0.921\end{array}$ & $\begin{array}{l}0.396 \\
0.526\end{array}$ & $\mathrm{Hi}=\mathrm{Lo}$ & 0.283 \\
\hline $\begin{array}{ll}\text { Site } & \\
& \text { High } \\
& \text { Low }\end{array}$ & $\begin{array}{l}8 \\
8\end{array}$ & $\begin{array}{l}0.251 \\
0.394 \\
0.109\end{array}$ & $\begin{array}{l}5.060 \\
3.618\end{array}$ & $\begin{array}{r}<0.001 \\
0.044\end{array}$ & $\mathrm{Hi}=\mathrm{Lo}$ & 5.882 \\
\hline $\begin{array}{ll}\text { Plot } & \\
& \text { High } \\
& \text { Low }\end{array}$ & $\begin{array}{l}24 \\
24\end{array}$ & $\begin{array}{l}0.050 \\
0.049 \\
0.050\end{array}$ & $\begin{array}{l}2.230 \\
0.974\end{array}$ & $\begin{array}{r}<0.001 \\
0.525\end{array}$ & $\mathrm{Hi}=\mathrm{Lo}$ & 2.398 \\
\hline $\begin{array}{l}\text { Photo } \\
\text { High } \\
\text { Low }\end{array}$ & $\begin{array}{l}144 \\
144\end{array}$ & $\begin{array}{l}0.022 \\
0.022 \\
0.022\end{array}$ & $\begin{array}{l}1.073 \\
1.015\end{array}$ & $\begin{array}{l}0.197 \\
0.463\end{array}$ & $\mathrm{Hi}=\mathrm{Lo}_{0}$ & 0.670 \\
\hline $\begin{array}{c}\text { Residual } \\
\text { High } \\
\text { Low }\end{array}$ & $\begin{array}{rr}3240 & \\
& 1620 \\
& 1620\end{array}$ & $\begin{array}{l}0.021 \\
0.021 \\
0.021\end{array}$ & 1.002 & 0.476 & $\mathrm{Hi}=\mathrm{Lo}$ & 90.77 \\
\hline
\end{tabular}


Table 8. Results of the nested ANOVA for patch scale Cochran's test showed homogenous variances with a logarithmic transformation $(C=0.0445, d f=72,4, p>0.05)$. Significant values in bold

\begin{tabular}{|lrcccc|}
\hline Source & df & $\begin{array}{c}\text { Mean } \\
\text { squares }\end{array}$ & $F$ & $\begin{array}{r}\text { p-value } \\
\text { variance } \\
\text { component } \\
\text { (\% of total) }\end{array}$ \\
\hline Area & 1 & 0.811 & 7.608 & 0.033 & - \\
Shore & 6 & 0.107 & 0.173 & 0.980 & 0 \\
Site & 16 & 0.618 & 1.471 & 0.151 & 2.173 \\
Plot & 48 & 0.419 & 0.708 & 0.926 & 0 \\
Residual & 288 & 0.593 & & & 98.827 \\
\hline
\end{tabular}

the size measurements in each quadrat showed significant differences at the area level $(10 \mathrm{~km})$, with $99 \%$ of the variation found within the residuals (Table 8 ). The north of Anglesey had a constant patch size below $25 \mathrm{~cm}^{2}$ ( $z$-test, $z=2.541, \mathrm{p}<0.05$ ), whereas the south had no constant patch size ( $z$-test, $z=1.071, \mathrm{p}>0.05$ ) below the scale of the quadrat.

\section{DISCUSSION}

\section{Evaluating the qualitative predictions of Roughgarden et al.'s (1985) model}

We tried to categorise the appropriate scale, provide evidence for Roughgarden et al.'s (1985) model by investigation of the qualitative predictions of the model, and see how robust these predictions are in a different system. The predictions were investigated using empirical observations of Semibalanus balanoides on a number of scales.

Roughgarden et al. (1985) predicted from their model that on small scales areas of high recruitment should have fewer cohorts, i.e. less variability in size, and on average less free space. However, on larger scales $\left(>34.6 \mathrm{~cm}^{2}\right)$ areas of high recruitment should have more variability in size between quadrats. We found there was no difference in the average free space, population variation or size variation at small scales. However, at the $100 \mathrm{~m}$ scale (or the maximum area for an open system) we found that there was strong evidence for more variability in size, supporting the prediction of the model of Roughgarden et al. (1985). Thus, the most robust qualitative prediction of Roughgarden et al.'s (1985) model seemed to be that size is more variable in areas with higher recruitment at large scales. A recruitment difference of 2 times is sufficient to suggest this prediction, as opposed to the differences of 20 times found by Gaines \& Roughgarden (1985). Correlations of population variance with free space were negative, the opposite of the model predictions.
There are a number of possible reasons for the difference between the model's predictions and empirical observations on free space. These include variable patch sizes, insufficient spatial sampling, insufficient recruitment difference, difference in mortality and/or growth rates and incorrect model assumptions. One of the implicit assumptions of the demographic model is that patches occur at a single spatial scale. If the temporal oscillations and cohort structures predicted by the demographic model are to be detected, observations must be made at or below this fundamental patch scale. Most of the variability in this study was at the smallest scale. Hence the patch scale, if it exists, must be at the smallest scales measured. Tests on the ratio of population variance to size variance suggested that a consistent patch scale existed below $25 \mathrm{~cm}^{2}$ in the low recruitment area, but not in the high recruitment area. Thus, in at least one of the areas sampled, the assumption of a fundamental patch scale is violated, and there is no appropriate quadrat size for the model predictions. It is not clear why one side of Anglesey should have consistent spatial structure below $25 \mathrm{~cm}^{2}$ when the other side of the island does not. Possible explanations are differences in wave action or limpet densities (patches of bare rock are created in the barnacle matrix when a limpet dies). The qualitative predictions that free space is on average less and small-scale population variance is on average higher in areas of lower recruitment are temporally and spatially averaged measures. The model predicts that in areas of high recruitment free space oscillates over time, but on average should be greater than in areas of low recruitment. The test provided here used spatial replication to look at average free space. Thus, insufficient replication in space could cause the observed difference between model predictions and empirical observations. A second possible explanation is insufficient difference in recruitment. In this study we had about twice the recruitment in high than low recruitment areas. However, the original model has 20 times the recruitment in the high areas than in the low areas (Gaines \& Roughgarden 1985). Thus, the difference could be insufficient to produce differences in free space or population variance.

The study is confounded as we only have one replicate in the factor area of recruitment. Thus, growth and/or mortality could co-vary with recruitment at this scale. This is a possibility as large spatial variation in growth rate (Bertness et al. 1991) and mortality has been observed. Finally, the model assumptions could be wrong. The most likely assumption that could be wrong is that there is no seasonality in the model. Semibalanus balanoides has a single settlement season between March and June (Hawkins \& Hartnoll 1982, Kendall et al. 1982), whereas Balanus glandula 
has a main settlement season with occasional peaks throughout the year (see Shkedy \& Roughgarden 1997 for data between 1989 and 1992).

This study does not give much evidence to support the qualitative predictions of the model of Roughgarden et al. (1985). However, it is difficult to evaluate model predictions from empirical or experimental data as many alternative hypotheses are usually possible for these patterns. The differences in size structure between areas observed in this study could be produced by skewed size distributions arising from much simpler explanations than the model of Roughgarden et al. (1985). For example, later settlement in the south, faster growth in the north or perhaps greater settlement in the south. Oscillations in free space ('oscillatory fingerprint') could also be caused by many different mechanisms. For example, recruitment pulses associated with seasonality (Hawkins \& Hartnoll 1982) or frontal advection (Eggleston et al. 1998), or variable predation (Minchinton \& Scheibling 1991). Thus, evidence of pattern does not necessarily imply the applicability of the model mechanisms, as many mechanisms could have caused the pattern. Evidence for the model could be collected in a number of ways. For example, a study of this type where recruitment growth and mortality are well categorised over large spatial scales and areas are interspersed and repeated in time would be a useful experimental study of this model. A more extensive version of the study by Gaines et al. (1985) on Semibalanus balanoides would also add evidence to the application of this model to a variety of spatial scales. Finally, settlement density could be manipulated (e.g. Denley \& Underwood 1979) across large spatial scales for many years. Monitoring of growth, mortality and free space simultaneously would allow the investigation of the oscillatory fingerprint, and population structure could be examined after around $8 \mathrm{yr}$ (double the maximum life span of $S$. balanoides, see Stubbings 1975). However, the logistic and financial constraints on such long-term studies mean that, in general, model predictions will have to be investigated by repeated small-scale studies of the kind presented here.

\section{Spatial scales of variation}

Observation of spatial variability in a variable is often the starting point from which questions and hypotheses about a system are composed (Weins 1989 , Levin 1992). Spatial variability can mediate processes such as predation, competition and reproduction. Significant variation implies the correct scales for manipulative experiments to test competing hypotheses about these processes. In this study we looked at a log- arithmic set of spatial scales from metres to greater than $10 \mathrm{~km}$.

We found variation in recruitment, patch scale and size at the $10 \mathrm{~km}$ scale. Differences at this scale have been linked with the transport of larvae. For example, upwelling (Roughgarden et al. 1987), estuarine flushing (Gaines \& Bertness 1992), and oceanographic currents (Hare \& Cowen 1993). Population processes can also vary at these scales, for example, growth (Bertness et al. 1991) and mortality due to differences in disturbance (Gaines \& Roughgarden 1985).

Free space is the only variable to show significant variation between shores $(\mathrm{km})$. This is possibly due to the variation in free space between Porth Nobla and the other high recruitment shores. Porth Nobla has an average proportional free space of 0.36 and the others are all around 0.25 . This may be due to Porth Nobla having a higher frequency of disturbance events on the scale of the photographs, as the shore is much more broken than the 3 other high recruitment shores (Gaines \& Roughgarden 1985, Possingham et al. 1994). The other variables do not vary at the shore level, possibly because this is between the scales at which mesoand large-scale oceanographic processes affect populations.

Free space, population variation and size varied on the mesoscale $(100 \mathrm{~m})$, or the limit to the scale of an open population (Roughgarden et al. 1985). This difference could be due to factors influencing the concentration of larvae and rate of larval arrival or variation in the mortality and/or growth rate. The larval concentration and rate of arrival are influenced by hydrodynamic processes such as surface waves, currents, internal wave and tidal bores (Hawkins \& Hartnoll 1982, Shanks 1983, 1986, Gaines \& Bertness 1992, Pineda 1994). Mortality and/or growth rate can also be influenced by hydrodynamic processes, in terms of increased food supply causing increased growth rate (Bertness et al. 1991), and increased disturbance (Gaines \& Roughgarden 1985).

There is a large amount of variation within replicates in all the variables ( 72 to $99 \%$ variance). This is not uncommon in studies of this nature (e.g. Lindergarth et al. 1994. Underwood \& Chapman 1996, Åberg \& Pavia 1997). This suggests that important structuring processes occur at a scale below the minimum scale in this study (Åberg \& Pavia 1997). Many processes have been suggested to occur on scales smaller than $1 \mathrm{~m}$, for example, larval settlement behaviour (e.g. Crisp \& Meadows 1962) and small-scale hydrodynamic processes (Butman 1987, Eckman 1990, Pawlik et al. 1991).

In this study, significant spatial variation was found at small $(<1 \mathrm{~m})$, meso- $(100 \mathrm{~m})$ and large scales $(>10 \mathrm{~km})$. Thus, future demographic studies of Semibalanus balanoides should concentrate on investiga- 
tions at these scales. A simultaneous study of variation in larval supply, recruitment, growth and mortality would be useful to understand the processes that structure the adult population.

Acknowledgements. We gratefully acknowledge the support of the Wellcome Trust Biomathematics Training Scheme for funding K.H. We thank. Per Ảberg and Per Nilsson for helpful comments on the manuscript and discussion of statistics as a part of EUROROCK (an EU funded project under the MAST initiative contract MAS3-CT95-0012). S.J.H. received support from the EUROROCK program. We thank Tania Alvarez and Richard Thompson for useful comments on the manuscript the Coastal Surveillance Unit (Bangor, Wales), who provided the data from the 1970 s and early 1980s and Sheila Bennell who was helpful during the fieldwork. Thanks also to the 4 referees for their constructive comments on the manuscript.

\section{LITERATURE CITED}

Aberg P, Pavia H (1997) Temporal and multiple scale spatial variation in juvenile and adult abundance of the brown alga Ascophyllum nodosum. Mar Ecol Prog Ser 158:111-119

Alexander SE, Roughgarden J (1996) Larval transport and population dynamics of intertidal barnacles: a complex benthic/oceanic model. Ecol Monogr 66:259-275

Arnold DC (1977) Fecundity of Balanus balanoides in Passamaquoddy Bay. J Fish Res Bd Can 34:273-275

Barnes H, Barnes M (1968) Egg numbers, metabolic efficiency of egg production and fecundity: local and regional variations in a number of common barnacles. J Mar Biol Assoc UK 32:107-128

Barnes H, Powell HT (1953) The growth rate of Balanus balanoides and $B$. crenatus under varying conditions of submersion. J Mar Biol Assoc UK 32:107-127

Barnes $M$ (1992) The reproductive period and condition of penis in several species of common cirripedes. Oceanogr Mar Biol Annu Rev 30:483-525

Bence JR, Nisbet RM (1989) Space-limited recruitment in open systems: the importance of time delays. Ecology 70 : $1434-1441$

Bennell SJ (1981) Some observations on the littoral barnacle populations of north Wales. J Mar Res 5:227-240

Bertness MD, Gaines SD, Bermudez D, Sandford E (1991) Extreme spatial variation in the growth rate and reproductive output of the acorn barnacle Semibalanus balanoides. Mar Ecol Prog Ser 75:91-100

Bertness MD, Gaines SD, Wahle RA (1996) Wind-driven settlement patterns in the acorn barnacle Semibalanus balanoides. Mar Ecol Prog Ser 137:103-110

Bowman RS, Lewis JR (1977) Annual fluctuations in the recruitment of Patella vulgata L. J Mar Biol Assoc UK 57 : 793-815

Butman CA (1987) Larval settlement of soft sediment invertebrates: the spatial scales of pattern explained by active habitat selection and the emerging role of hydrodynamic processes. Oceanogr Mar Biol Annu Rev 25:113-165

Cochran WG (1951) Testing a linear relation among variances. Biometrics 7:17-32

Connell JH (1961) The effect of competition, predation by Thais lapillus and other factors on natural populations of the barnacle Balanus balanoides. Ecol Monogr 31:61-104

Connell JH (1983) On the prevalence and relative importance of interspecific competition: evidence from field experiments. Am Nat 122:661-696
Connell JH (1985) The consequence of initial settlement versus post-settlement mortality in rocky intertidal communities. J Exp Mar Biol Ecol 93:11-45

Crisp DJ (1964) Radical differences between North American and European form of Balanus balanoides. J Mar Biol Assoc UK 44:33-45

Crisp DJ, Meadows PS (1962) The chemical basis of gregariousness in cirripeds. Proc R Soc Lond Ser B 156:500-520

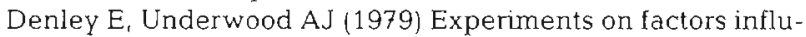
encing settlement, survival and growth of 2 species of barnacle in New South Wales. J Exp Mar Biol Ecol 36:269-295

Eckman JE (1990) A model of passive settlement by planktonic larvae onto bottoms of differing roughness. Limnol Oceanogr 35:887-901

Eggleston DB, Armstrong DA, Elis WE, Patton WS (1998) Estuarine fronts as conduits for larval transport: hydrodynamics and spatial distribution of Dungeness crab postlarvae. Mar Ecol Prog Ser 164:73-82

Gaines SD, Bertness MD (1992) Dispersal of juveniles and variable recruitment in sessile marine species. Nature 360:579-580

Gaines SD, Brown S, Roughgarden J (1985) Spatial variation in larval concentrations as a cause of spatial variation in settlement for the barnacle, Balanus glandula. Oecologia $67: 267-272$

Gaines SD, Lafferty KD (1995) Modelling the dynamics of marine species: the importance of incorporating larval dispersal. In: McEdward L (eds) Ecology of marine larvae. CRC Press Inc, Boca Raton, FL, p 389-412

Gaines SD, Roughgarden J (1985) Fish in offshore kelp forests affect recruitment to intertidal barnacle populations. Science 235:479-481

Gaines SD, Roughgarden J (1987) Larval settlement as a leading determinant of structure in an ecological community of the rocky intertidal. Proc Nat Acad Sci USA 82:3707-3711

Green RH (1979) Sampling designs and statistical methods for environmental biologists. John Wiley and Sons, New York

Hare JA, Cowen RK (1993) Ecological and evolutionary implications of the larval transport and reproductive strategy in an ecological of bluefish Pomatomus saltatrix. Mar Ecol Prog Ser 98:1-16

Hawkins SJ (1983) Interaction of Patella and macroalgae with settling Semibalanus balanoides (L.). J Exp Mar Biol Ecol 71:55-72

Hawkins SJ, Hartnoll RG (1982) Settlement patterns of Balanus balanoides (L.) in the Isle of Man. J Exp Mar Biol Ecol 62: $271-283$

Hillborn R. Mangel M (1997) The ecological detective. Princeton University Press, Princeton, NJ

Hills JM, Thomason JC (1996) A multi-scale analysis of settlement density and pattern dynamics of the barnacle Semibalanus balanoides. Mar Ecol Prog Ser 1.38.103-1.15

Hughes TP (1984) Population dynamics based on individual size rather than age: a general model with a coral reef example. Am Nat 123:778-795

Iwasa Y, Roughgarden J (1985) Evolution in a metapopulation with space-limited subpopulations. IMA (Inst Math Appl) J Math Appl Med Biol 2:93-107

Iwasa Y, Roughgarden J (1986a) Dynamics of a metapopulation with space-limited subpopulations. Theor Popul Biol 29:235-261

Iwasa $Y$, Roughgarden J (1986b) Interspecific competition among metapopulations with space-limited subpopulations. Theor Popul Biol 30:194-214

KendaIl MA, Bowman RS. Williamson P, Lewis JR (1982) Settlement patterns, density and stability in the barnacle Balanus balanoides. Neth J Sea Res 16:119-126 
Kendall MA, Bowman RS, Williamson P, Lewis JR (1985) Annual variation in the recruitment of Semibalanus balanoides on the North Yorkshire coast, 1969-1981. J Mar Biol Assoc UK 65:1009-1030

Kohyama T (1993) Size-structured tree populations in a gap dynamic forest - the forest architecture hypothesis for the coexistence of species. J Ecol 81:131-143

Levin SA (1992) The problem of pattern and scale in ecology. Ecology 73:1943-1967

Lindergarth M, Andre C, Jonsson PR (1994) Analysis of the spatial variability in abundance and age structure of two infaunal bivalves, Cerastoderma edule and C. lamarcki. using hierarchical sampling programs. Mar Ecol Prog Ser 116:85-97

Mapstone BD, Fowler AJ (1988) Recruitment and the structure of assemblages of fish on coral reefs. Trends Ecol Evol 3:72-75

Miller KM. Carefoot TH (1989) The role of spatial and size refuges in the interaction between barnacles and grazing limpets. J Exp Mar Biol Ecol 134:157-174

Minchinton TE, Scheibling RG (1991) The influence of larval supply and settlement on the population structure of barnacles. Ecology 72:1867-1879

Minchinton TE, Scheibling RG (1993) Variations in sampling procedure and frequency affect estimates of recruitment of barnacles. Mar Ecol Prog Ser 99:83-88

Nisbet RM, Bence JR (1989) Alternative dynamic regimes for canopy-forming kelp: a variant on density-vague population regulation. Am Nat 134:377-408

Pawlik JR, Butman CA, Starczak VR (1991) Hydrodynamic facilitation of gregarious settlement of a reef building tube worm. Science 251:421-424

Pineda J (1994) Spatial and temporal patterns in barnacle settlement rate along a southern California rocky shore. Mar Ecol Prog Ser 107:125-138

Possingham H, Roughgarden J (1990) Spatial population dynamics of a marine organism with a complex life cycle. Ecology 71:973-985

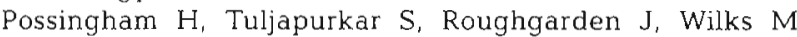
(1994) Population cycling in space limited organisms subject to density dependent predation. Am Nat 143: $563-582$

Richards SA, Possingham HP, Noye BJ (1995) Larval dispersion along a straight coast with tidal currents: complex distribution patterns from a simple model. Mar Ecol Prog Ser $122: 59-71$

Editorial responsibility: Otto Kinne (Editor),

Oldendorf/Luhe, Germany
Robles CD (1997) Changing recruitment in constant species assemblages: implications for predation theory in intertidal communities. Ecology 78:1400-1414

Roughgarden J, Iwasa Y, Baxter C (1985) Demographic theory for and open marine population with space-limited recruitment. Ecology 66:54-67

Roughgarden J, Gaines S, Pacala SW (1987) Supply side ecology: the role of physical transport processes. In: Gee $\mathrm{JH}_{\text {, }}$ Giller PS (eds) Organisation of communities - past and present. Blackwell Scientific, London, p 491-581

Roughgarden J, Gaines S, Possingham H (1988) Recruitment dynamics in complex life cycles. Science 241:1460-1466

Roughgarden J, Pennington T, Alexander S (1994) Dynamics of the rocky intertidal zone with remarks on generalization in ecology. Philos Trans R Soc Lond B 343:79-85

Sandford E, Bermudez D, Bertness MD, Gaines SD (1994) Flow, food supply and acorn barnacle population dynamics. Mar Ecol Prog Ser 104:49-62

Shanks AL (1983) Surface slicks associated with tidally forced internal waves may transport pelagic larvae of benthic invertebrates and fish shoreward. Mar Ecol Prog Ser 24:289-295

Shanks AL (1986) Tidal periodicity in the daily settlement of intertidal barnacle larvae and an hypothesised mechanism for the cross-shelf transport of cyprids. Biol Bull (Woods Hole) 170:429-440

Shkedy Y, Roughgarden J (1997) Barnacle recruitment and population dynamics predicted from coastal upwelling. Oikos 80:487-498

Sokal RR, Rohlf FJ (1995) Biometry, 3rd edn. WH Freeman and Company, New York

Stubbings HG (1975) Balanus balanoides. Liverpool University Press, Liverpool

Underwood AJ (1997) Experiments in ecology. Cambridge University Press, Cambridge

Underwood AJ, Chapman MG (1996) Scales of spatial patterns of distribution of intertidal invertebrates. Oecologia 107:212-224

Weins JA (1989) Spatial scaling in ecology. Funct Ecol 3:385-397

Wethey DS (1983) Intrapopulation variation in growth of sessile organisms: natural populations of the intertidal barnacle Balanus balanoides. Oikos 40:14-23

Wethey DS (1985) Local and regional variation in settlement and survival in the littoral barnacle Semibalanus balanoides (L.): patterns and consequences. In: Moore PG, Seed R (eds) The ecology of rocky coasts. Hodder and Stoughton Educational, London, p 194-202

Submitted: January 21, 1998; Accepted: August 6, 1998 Proots received from author(s): November 9, 1998 